\title{
Nickel Manganite-Sodium Alginate Nano-Biocomposite for Temperature Sensing
}

\author{
Milena P. Dojcinovic ${ }^{1}$, Zorka Z. Vasiljevic ${ }^{1}\left(\right.$, Janez Kovac $^{2}$, Nenad B. Tadic ${ }^{3}$ and Maria Vesna Nikolic ${ }^{1, *(1)}$ \\ 1 Institute for Multidisciplinary Research, University of Belgrade, 11030 Belgrade, Serbia; \\ milena.dojcinovic@imsi.rs (M.P.D.); zorkav@imsi.rs (Z.Z.V.) \\ 2 Jozef Stefan Institute, SI-1000 Ljubljana, Slovenia; janez.kovac@ijs.si \\ 3 Faculty of Physics, University of Belgrade, 11000 Belgrade, Serbia; nenad.tadic@ff.bg.ac.rs \\ * Correspondence: mariav@rcub.bg.ac.rs
}

Citation: Dojcinovic, M.P.; Vasiljevic, Z.Z.; Kovac, J.; Tadic, N.B.; Nikolic, M.V. Nickel Manganite-Sodium Alginate Nano-Biocomposite for Temperature Sensing. Chemosensors 2021, 9, 241. https://doi.org/ $10.3390 /$ chemosensors 9090241

Academic Editors: Elisabetta Comini and Ana Rovisco

Received: 9 July 2021

Accepted: 25 August 2021

Published: 27 August 2021

Publisher's Note: MDPI stays neutral with regard to jurisdictional claims in published maps and institutional affiliations.

Copyright: (c) 2021 by the authors. Licensee MDPI, Basel, Switzerland. This article is an open access article distributed under the terms and conditions of the Creative Commons Attribution (CC BY) license (https:// creativecommons.org/licenses/by/ $4.0 /)$.

\begin{abstract}
Nanocrystalline nickel manganite $\left(\mathrm{NiMn}_{2} \mathrm{O}_{4}\right)$ powder with a pure cubic spinel phase structure was synthesized via sol-gel combustion and characterized with XRD, FT-IR, XPS and SEM. The powder was mixed with sodium alginate gel to form a nano-biocomposite gel, dried at room temperature to form a thick film and characterized with FT-IR and SEM. DC resistance and AC impedance of sensor test structures obtained by drop casting the nano-biocomposite gel onto test interdigitated PdAg electrodes on an alumina substrate were measured in the temperature range of $20-50{ }^{\circ} \mathrm{C}$ at a constant relative humidity $(\mathrm{RH})$ of $50 \%$ and at room temperature $\left(25^{\circ} \mathrm{C}\right)$ in the $\mathrm{RH}$ range of $40-90 \%$. The material constant obtained from the measured decrease in resistance with temperature was determined to be $4523 \mathrm{~K}$, while the temperature sensitivity at room temperature $\left(25^{\circ} \mathrm{C}\right)$ was $-5.09 \% / \mathrm{K}$. Analysis of the complex impedance plots showed a dominant influence of grains. The decrease in complex impedance with increase in temperature confirmed the negative temperature coefficient effect. The grain resistance and grain relaxation frequency were determined using an equivalent circuit. The activation energy for conduction was determined as $0.45 \mathrm{eV}$ from the temperature dependence of the grain resistance according to the small polaron hopping model, while the activation energy for relaxation was $0.43 \mathrm{eV}$ determined from the Arrhenius dependence of the grain relaxation frequency on temperature.
\end{abstract}

Keywords: nickel manganite; sodium alginate; nano-biocomposite; NTC thermistor; temperature sensing

\section{Introduction}

Temperature monitoring is necessary in a wide range of applications, such as the biomedical, domestic and industrial sectors. Negative temperature coefficient (NTC) ceramic thermistors are the traditional industrial standard for temperature sensing, due to their high sensitivity (generally between $-2 \% / \mathrm{K}$ and $-6 \% / \mathrm{K}$ at room temperature of $25{ }^{\circ} \mathrm{C}$ ), low cost, abundance and excellent stability [1]. Different oxides have been applied and investigated as NTC thermistor materials, but the focus remains on cubic spinels with the molecular formula $\mathrm{AB}_{2} \mathrm{O}_{4}$. In a normal spinel structure the tetrahedral (A) site is occupied by the divalent ion, and the octahedral (B) site is occupied by the trivalent ion [1,2]. $\mathrm{NiMn}_{2} \mathrm{O}_{4}$ is one the most studied materials for NTC thermistor applications and still remains the focus of current research [2-4]. It has a mixed cubic spinel structure where $\mathrm{A}\left(\mathrm{Ni}^{2+}\right)$ and $\mathrm{B}\left(\mathrm{Mn}^{3+}, \mathrm{Mn}^{4+}\right)$ cations can occupy both tetrahedral and octahedral sites. Thermally activated polaron hopping between $\mathrm{Mn}^{3+}$ and $\mathrm{Mn}^{4+}$ cations at octahedral sites is responsible for conduction in $\mathrm{NiMn}_{2} \mathrm{O}_{4}$ [5], though recent research has shown that the thermal properties of nickel manganite can be also modified by tuning cations on the tetrahedral sites [2]. NTC thermistors with high stability and low room temperature resistivity have been achieved, and shown to depend on the synthesis and processing methods [6-8] and composition (improved with cation substitution) [8-10]. This makes 
nickel manganite a tunable and versatile NTC thermistor material for temperature sensing, especially when high sensitivity is needed.

Prospective applications for temperature sensing include artificial/electronic skin and soft robotics [11,12], or wearable sensors for remote health and environment monitoring $[13,14]$. The temperature of the human body is one factor that can reflect overall health [15] and is one of the significant parameters monitored during the current COVID19 pandemic [16]. There is a growing interest in flexible devices, including temperature sensors, and much research has been devoted to this subject [17]. There are several types of flexible temperature sensors, including resistance temperature sensors, thermocouples and thermistors. Thermistors are most often applied when small changes in temperature need to be detected. Sensing materials used in flexible temperature sensing include carbon, metals and metal oxides, polymers and organic materials [15]. Much research has focused on printed temperature sensors $[11,18]$, as these are simple to produce, easily reproducible and can be scaled up to large areas. Other techniques for the development of flexible temperature sensors include textile-based techniques and coating and deposition techniques [17]. Coating and deposition is used to obtain thin or thick layers of the sensing nanomaterial on a flexible substrate and includes spray coating, spin coating, dip coating, drop casting and doctor blading techniques. One of the requirements for artificial skin or epidermal sensors is high temperature sensitivity, in order to be able to capture relatively small temperature changes at approximately room temperature [12]. One of the advantages of using NTC thermistor oxides in flexible temperature sensing, especially human body temperature sensing, is their low cost and simple structure combined with high temperature sensitivity [12]. One of the current challenges is to develop temperature sensors that can combine the reliable performance of NTC thermistors with a flexible substrate and viable insulating polymer binder [11]. The thermistor oxide particles define the electrical properties, while the polymer binder defines the environment and mechanical stability [11]. In contact with the environment, especially humidity, the polymer often swells and loses stability. Another issue is poor adhesion to the chosen substrate. Wearable temperature sensors for monitoring the human body temperature can also be designed as a mixture of conductive materials and temperature sensitive polymers in the form of conductive polymer composites [12,19], such as a Ni microparticle-filled binary polymer composite [20].

One of the trends in wearable electronics is the development of biodegradable components in order to reduce environmental pollution and improve biocompatibility. The motivation for this work was to analyze the possibility of using a biodegradable polymer as a polymer binder in combination with a NTC thermistor oxide as a potential temperature sensing material to be applied by the simple technique of drop casting. Sodium alginate was chosen as it is a natural polymer of the polysaccharide family [21]. In its natural form alginate has low stability, high porosity and rapid degradation, so it is commonly enhanced with nanoparticles [22], forming nano-biocomposites in the form of hydrogels, films and fibers for biomedical applications [23,24] or biodegradable food packaging [25]. Though there is no research to our knowledge on using sodium alginate gel for temperature sensing, it has been analyzed as a nano-biocomposite in combination with copper oxide for amperometric glucose biosensing [26]. In this case alginate gel was used as the immobilization matrix, while nanoparticles provided stability to the film as fillers and introduced new properties to the hydrogel, such as excellent electrical properties, chemical passivity and thermal stability. Nickel manganite was selected as the NTC thermistor component in the composite, as it has high temperature sensitivity. The sol-gel combustion method was selected for nickel manganite nanopowder synthesis as it is simple and can easily be scaled up for mass production of nanomaterials with desired morphologies, good reproducibility [27,28] and a single phase $\mathrm{NiMn}_{2} \mathrm{O}_{4}$ cubic spinel structure [29]. In this work, we performed initial investigation of combining nanocrystalline nickel manganite obtained using the sol-gel combustion method with sodium alginate gel to form a nanobiocomposite gel, applied by drop casting onto a flexible Kapton substrate to obtain a film 
at room temperature. Its suitability for application in temperature sensing was tested by drop casting the gel onto test interdigitated $\mathrm{PdAg}$ electrodes on an alumina substrate.

\section{Materials and Methods}

\subsection{Materials}

Nickel nitrate hexahydrate $\left(\mathrm{Ni}\left(\mathrm{NO}_{3}\right)_{2} \cdot 6 \mathrm{H}_{2} \mathrm{O}\right)$, manganese nitrate tetrahydrate $\left(\mathrm{Mn}\left(\mathrm{NO}_{3}\right)_{2}\right.$. $\left.4 \mathrm{H}_{2} \mathrm{O}\right)$, citric acid $\left(\mathrm{C}_{6} \mathrm{H}_{8} \mathrm{O}_{7}\right)$, glycine $\left(\mathrm{C}_{2} \mathrm{H}_{5} \mathrm{NO}_{2}\right)$ and deionized water were purchased from Sigma Aldrich (Darmstadt, Germany), while alginic acid sodium salt was purchased from Alfa Aesar (Thermo Fisher Scientific, Haverhill, MA, USA), calcium chloride $\left(\mathrm{CaCl}_{2}\right)$ from Lach-ner Chemicals (Neratovice, Czech Republic) and glycerol $\left(\mathrm{C}_{3} \mathrm{H}_{8} \mathrm{O}_{3}\right)$ from Galafarm (Belgrade, Serbia).

\subsection{Preparation and Characterization of Nickel Manganite Powder}

The sol-gel combustion synthesis method with glycine as fuel was used as the chosen synthesis method for obtaining pure cubic spinel phase nickel manganite nanoparticles. The metal nitrates were dissolved in distilled water at a molar ratio of 1:2 (Ni:Mn) with a few drops of citric acid added to the solution. Glycine was separately dissolved in distilled water. The mixture of both solutions was stirred in a magnetic mixer for $1 \mathrm{~h}$ at $60{ }^{\circ} \mathrm{C}$ and $2 \mathrm{~h}$ at $90{ }^{\circ} \mathrm{C}$, resulting in a green gel. This gel was heated up on a hot plate leading to intense self-ignition of the gel and formation of porous black foamy ash. This powder was calcined at $800{ }^{\circ} \mathrm{C}$ in a chamber furnace. Structural characterization was performed using X-ray diffraction (Rigaku Ultima IV diffractometer, Tokyo, Japan) in the range of 10-90 and FT-IR spectrocopy (FT-IR Nicolet 6700 ATR, Thermo Fisher Scientifics, Waltham, MA, USA) in the range of $400-4000 \mathrm{~cm}^{-1}$ with a resolution of $4 \mathrm{~cm}^{-1}$. The elemental composition and chemical state of elements in the synthesized nickel manganite powder were determined by recording X-ray photoelectron spectra (XPS) on a PHI-TFA XPS spectrometer (Physical Electronics Inc., ULVAC-PHI, Chigasaki, Japan) equipped with an Al-monochromatic X-ray source. The analyzed area was $0.4 \mathrm{~mm}$ in diameter and the analyzed depth was approximately $3-5 \mathrm{~nm}$. The accuracy of binding energies was about $\pm 0.7 \mathrm{eV}$. A low energy electron gun was used for charge compensation, and the $\mathrm{C} 1 \mathrm{~s}$ spectrum was aligned to $284.8 \mathrm{eV}$ due to surface contamination. XPS spectra were fitted with Gauss-Lorentz functions and the Shirley function was used for background removal. Powder morphology was observed via scanning electron microscopy (SEM) (TESCAN Electron Microscope VEGA TS 5130MM, Brno, Czech Republic).

\subsection{Preparation and Characterization of Nickel Manganite-Alginate Nano-Biocomposite Films}

Sodium alginate gel was produced by dissolving the alginic sodium salt in deionized water in a magnetic mixer for $6 \mathrm{~h}$ at room temperature and adding a calcium chloride cross-linking agent and glycerol at the end, followed by gentle mixing. Synthesized nickel manganite powder $(0.1 \mathrm{~g})$ was added to the gel $(5 \mathrm{~g})$ and mixed via ultrasonic dispersion for $5 \mathrm{~min}$. The nano-biocomposite gel was drop casted onto a Kapton substrate and left to dry at room temperature for several days to form a film (Figure 1). The film structure was observed using FT-IR spectroscopy (Perkin Elmer Spectrum Two, USA) and the morphology using SEM (TESCAN Electron Microscope VEGA TS 5130MM, Brno, Czech Republic). 


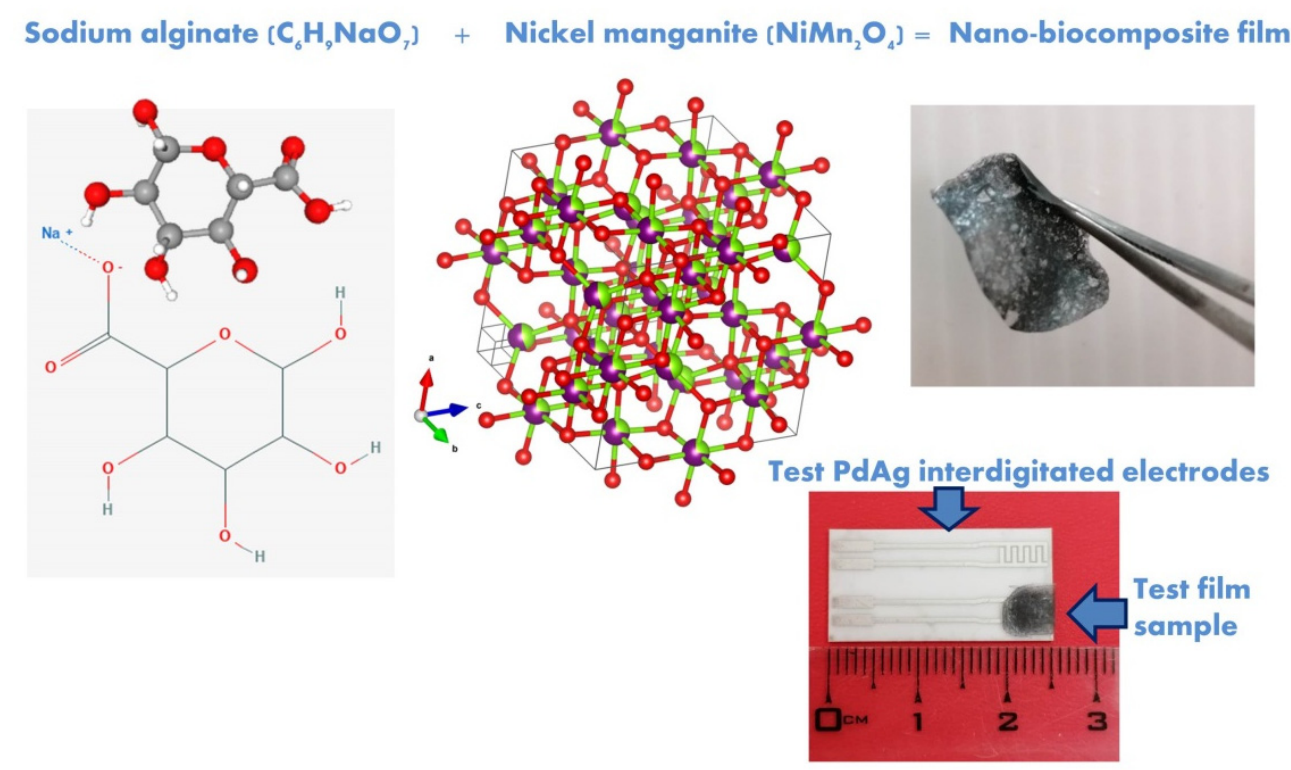

Figure 1. Nickel manganite $\left(\mathrm{NiMn}_{2} \mathrm{O}_{4}\right)$-sodium alginate nano-biocomposite film image (upper right); test interdigitated electrodes with and without film (lower right); crystal structure of $\mathrm{NiMn}_{2} \mathrm{O}_{4}$ drawn using VESTA [30] (center); sodium alginate 2D and 3D structure images [31,32] (left).

\subsection{Temperature Sensing Experiment}

Samples for DC resistance and AC impedance measurements were prepared by drop casting the prepared nano-biocomposite gel onto an alumina substrate with small test PdAg interdigitated electrodes (finger width $0.6 \mathrm{~mm}$, finger spacing $0.3 \mathrm{~mm}$ as shown in Figure 1 and in more detail in $[33,34])$ and leaving it to dry and age at room temperature for several days. Measurement of the temperature dependence of DC resistance (NTC characteristic) and AC impedance was conducted on a HIOKI IM3536 LCR meter in a JEIO TECH TH-KE 025 temperature and humidity climatic chamber in the temperature range of $20-50{ }^{\circ} \mathrm{C}$ (step $5{ }^{\circ} \mathrm{C}$ ) with relative humidity $(\mathrm{RH})$ maintained at $\mathrm{RH} 50 \%$. AC impedance was measured in the frequency range $8 \mathrm{~Hz}-1 \mathrm{MHz}$, with the voltage set to $1 \mathrm{~V}$. In order to monitor the influence of changes in relative humidity on the DC resistance and AC impedance, measurements were also performed at a constant temperature of $25^{\circ} \mathrm{C}$ with the $\mathrm{RH}$ varying from $40-90 \%$, as well as in the frequency range of $8 \mathrm{~Hz}-1 \mathrm{MHz}$ with the voltage set to $1 \mathrm{~V}$.

\section{Results and Discussion}

\subsection{Structure and Morphology of $\mathrm{NiMn}_{2} \mathrm{O}_{4}$ Powder}

Measured XRD patterns of $\mathrm{NiMn}_{2} \mathrm{O}_{4}$ powder after combustion and calcination at $800{ }^{\circ} \mathrm{C}$ are shown in Figure 2. The black ash created by sol-gel combustion was amorphous, with small peaks indicating the start of the formation of nickel manganite noticeable at (311), (220), (400) and (440). Calcination resulted in pure-phase, sharp, well-defined and high-intensity peaks that can be attributed to the $F d \overline{3} m$ cubic spinel structure according to ICCD/JCPDS card 71-0852 [35]. 


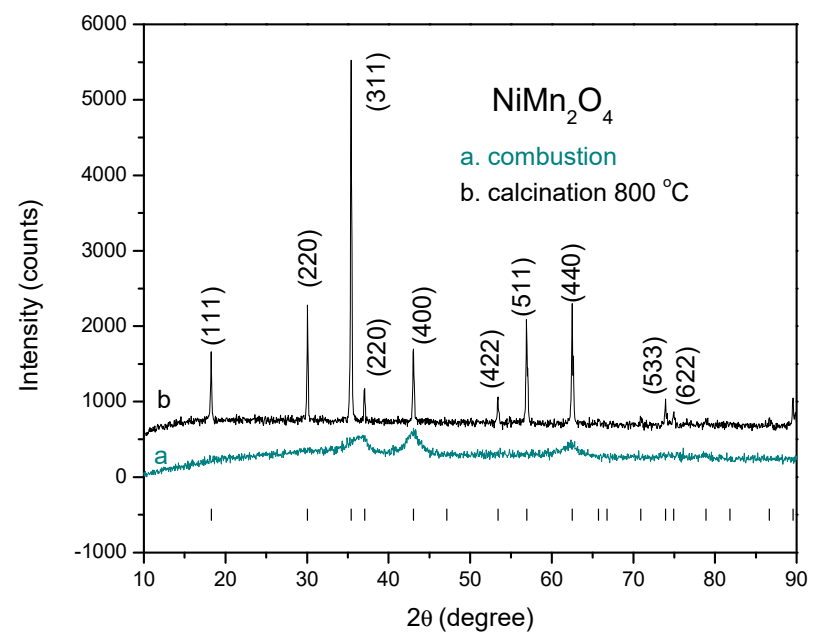

Figure 2. X-ray diffraction patterns of $\mathrm{NiMn}_{2} \mathrm{O}_{4}$ powder after combustion (a) and calcination (b), peaks marked according to JCPDS card 71-0852.

Measured FT-IR spectra are shown in Figure 3. After combustion there were almost no organic compounds present in the powder except for a small incline representing a combination of residual vibrations in the nitrate groups from the manganese and nickel nitrate precursors, expected at 1620 and $1380 \mathrm{~cm}^{-1}$, and the stretching band of the carboxylate anion $\left(\mathrm{COO}^{-}\right)$, expected in the range of $1650-1550 \mathrm{~cm}^{-1}$ [36,37]. A small peak at approximately $590 \mathrm{~cm}^{-1}$ shows the start of $\mathrm{NiMn}_{2} \mathrm{O}_{4}$ formation in the form of metal oxygen bonds. After calcination, only vibration bands originating from tetrahedral and octahedral groups of $\mathrm{Mn}^{3+}-\mathrm{O}^{2-}$ and $\mathrm{Ni}^{2+}-\mathrm{O}^{2-}$ were noted at approximately 571,500 and $406 \mathrm{~cm}^{-1}[35,38]$.

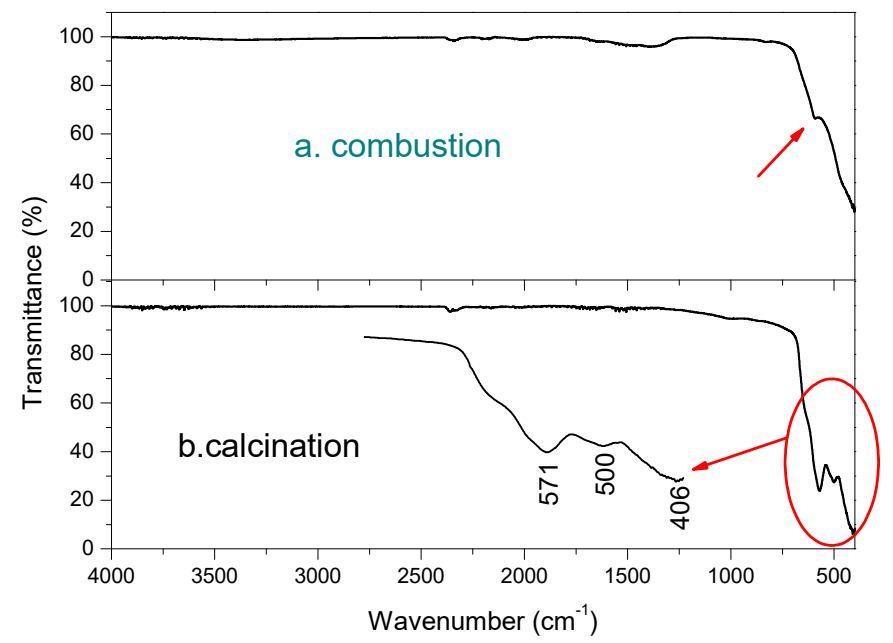

Figure 3. FT-IR spectra of NiMn2O4 powder after combustion (a) and calcination (b).

Photoelectron peaks corresponding to $\mathrm{C}, \mathrm{O}, \mathrm{Mn}$ and $\mathrm{Ni}$ were identified in the recorded survey XPS spectrum, as previously noted for spinel nickel manganite [36]. Oxidation states of elements were analyzed [39] and the recorded high energy resolution XPS spectra for Mn 2p and Ni 2p are shown in Figure 4. The Mn 2p spectra consisted of doublet Mn $2 \mathrm{p}_{3 / 2}$ and $\mathrm{Mn} 2 \mathrm{p}_{1 / 2}$ separated by $11.7 \mathrm{eV}$. This value of spin-orbit splitting was previously noted for spinel nickel manganite [40,41]. Mn 2 $\mathrm{p}_{3 / 2}$ spectra were deconvoluted into three components: peak Mn-1 at $639.2 \mathrm{eV}$ assigned to $\mathrm{Mn}^{2+}$, peak $\mathrm{Mn}-2$ at $641.3 \mathrm{eV}$ assigned to $\mathrm{Mn}^{3+}$ and peak Mn-3 at $643.5 \mathrm{eV}$ assigned to either a satellite peak of $\mathrm{Mn}$ or to $\mathrm{Mn}^{4+}$. The relative portion of Mn-1 $\left(\mathrm{Mn}^{2+}\right)$ peak inside the total $\mathrm{Mn} 2 \mathrm{p}_{3 / 2}$ peak was $9.8 \%$. The presence of $\mathrm{Mn}$ in all three valences has also been previously noted for cubic spinel nickel 
manganite [41,42]. The Ni $2 \mathrm{p}_{3 / 2}$ spectra consisted of a peak Ni-1 at $854.5 \mathrm{eV}$, which may be assigned to $\mathrm{Ni}^{2+}$, and a peak $\mathrm{Ni}-2$ at $856.6 \mathrm{eV}$, which may be assigned to the $\mathrm{Ni}^{3+}$ state. There were also peaks Ni-3 and Ni-4 at $860.1 \mathrm{eV}$ and $862.2 \mathrm{eV}$, which are the Ni $2 \mathrm{p}_{3 / 2}$ satellite peaks. Both $\mathrm{Ni}^{2+}$ and $\mathrm{Ni}^{3+}$ states for $\mathrm{Ni}$ were also noted by Ray et al. [36].

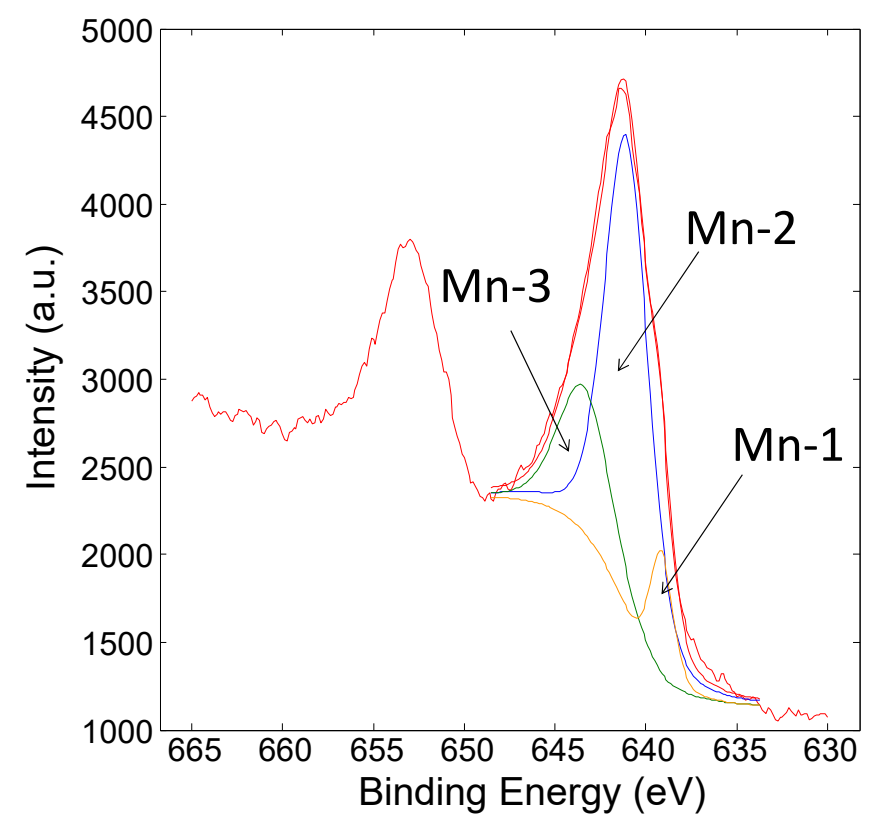

(a)

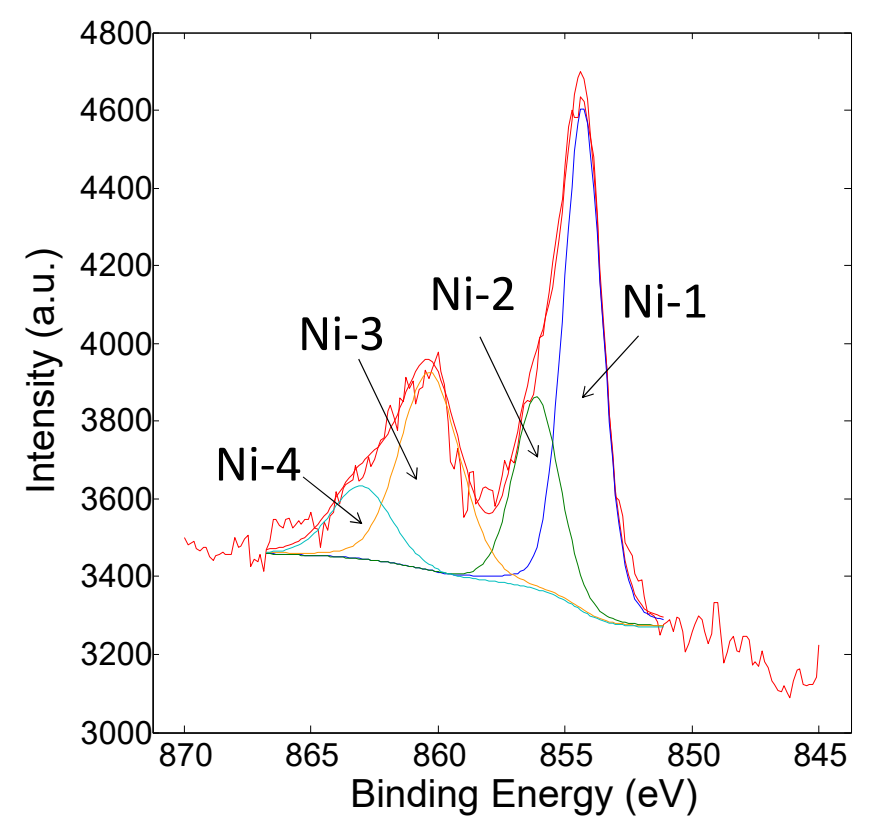

(b)

Figure 4. XPS spectra of $\mathrm{NiMn}_{2} \mathrm{O}_{4}$ powder $\mathrm{Mn} 2 \mathrm{p}(\mathbf{a})$ and $\mathrm{Ni} 2 \mathrm{p}(\mathbf{b})$.

Figure 5 shows the foamy ash-like amorphous powder obtained after combustion (a), while calcination at $800{ }^{\circ} \mathrm{C}$ created agglomerated $150-200 \mathrm{~nm}$ particles of nanocrystalline $\mathrm{NiMn}_{2} \mathrm{O}_{4}$ (b).

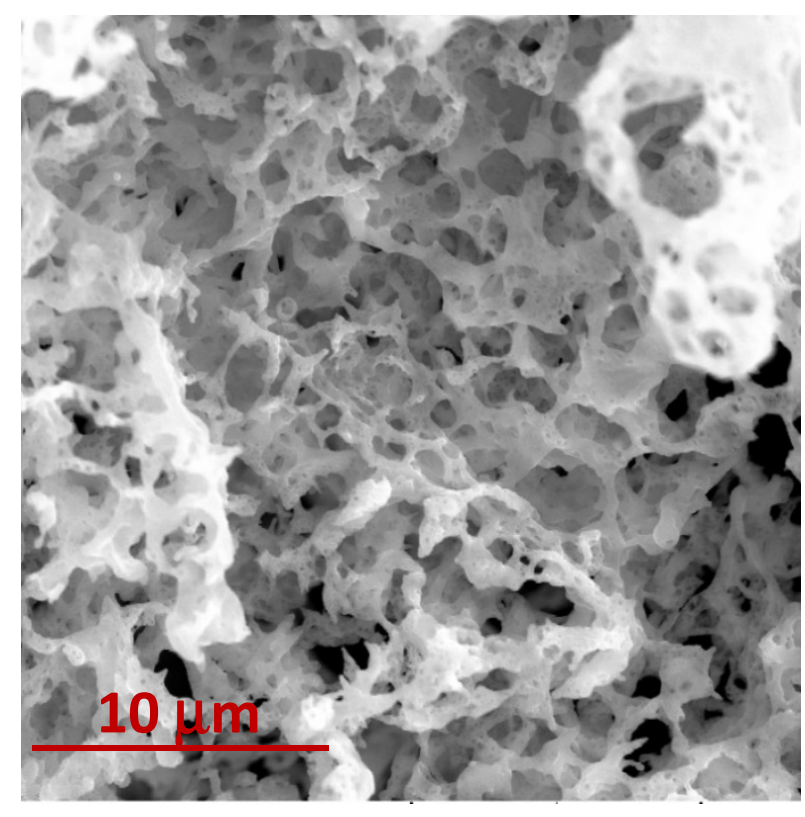

(a)

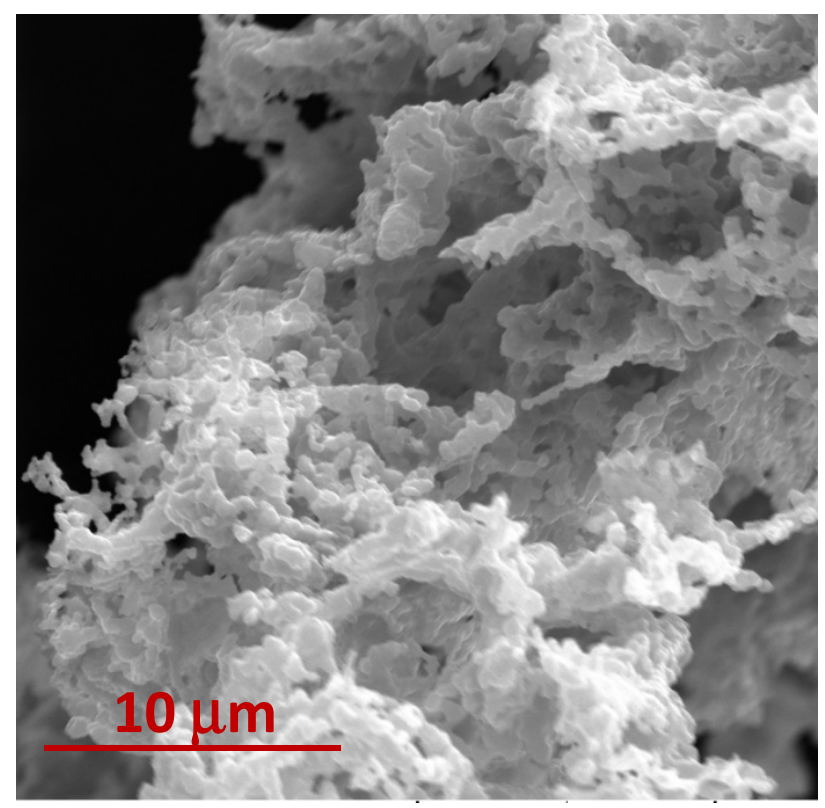

(b)

Figure 5. SEM images of $\mathrm{NiMn}_{2} \mathrm{O}_{4}$ powder after combustion (a) and calcination (b). 


\subsection{Structure and Morphology of $\mathrm{NiMn}_{2} \mathrm{O}_{4}$-Alginate Nano-Biocomposite}

The FT-IR spectrum of the $\mathrm{NiMn}_{2} \mathrm{O}_{4}$-alginate nano-biocomposite film is shown in Figure $6 \mathrm{a}$. The $\mathrm{O}-\mathrm{H}$ stretching band can be noted at $\approx 3274 \mathrm{~cm}^{-1}$ in accordance with the literature [43-45]. The bands at $\approx 2920 \mathrm{~cm}^{-1}$ can be assigned to the $\mathrm{CH}$ anomer [43], while strong asymmetric $\mathrm{COO}^{-}$stretching vibrations can be noted at $\approx 1604 \mathrm{~cm}^{-1}$, accompanied by $\mathrm{COO}^{-}$symmetric stretching vibrations at $\approx 1410 \mathrm{~cm}^{-1}$ reflecting metal-carboxylate interactions [43,45]. The strong band at $\approx 1030 \mathrm{~cm}^{-1}$ is due to $\mathrm{C}-\mathrm{O}$ stretching vibrations $[43,45]$. The bands between 800 and $1000 \mathrm{~cm}^{-1}$ may be due to mannuronic acid residues, $\mathrm{C} 1-\mathrm{H}$ deformation of mannuronic acid residues and $\mathrm{CO}$ stretching of uronic acids, which are part of the structure of alginic acid [43]. All these bands originated from the sodium alginate film. The bands in the region $400-600 \mathrm{~cm}^{-1}(560,487$ and 406) are vibration bands originating from tetrahedral and octahedral groups of $\mathrm{Mn}^{3+}-\mathrm{O}^{2-}$ and $\mathrm{Ni}^{2+}-\mathrm{O}^{2-}$ and are in accordance with the FT-IR spectrum of the $\mathrm{NiMn}_{2} \mathrm{O}_{4}$ powder analyzed above (Figure 3).

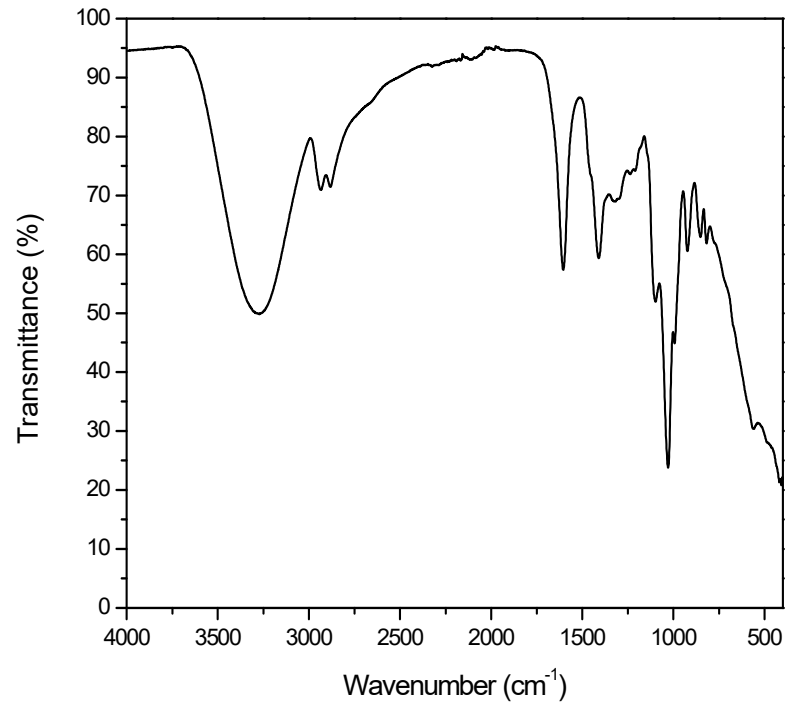

(a)

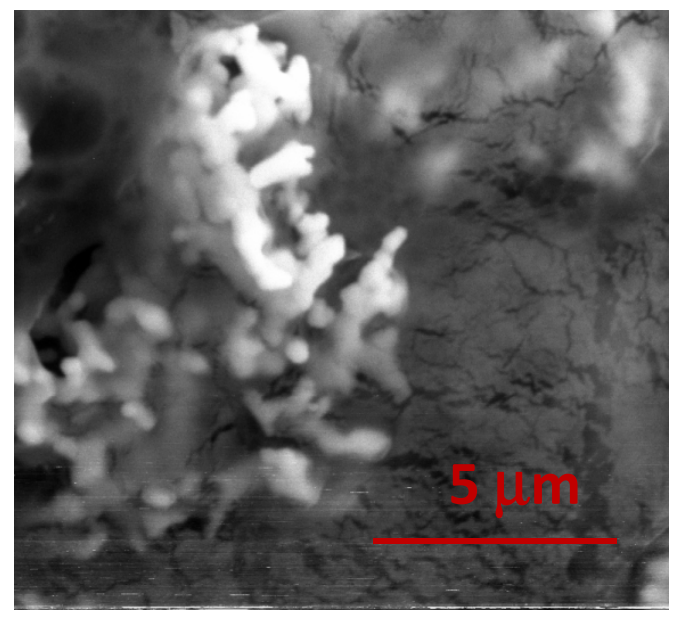

(b)

Figure 6. FT-IR spectrum (a) and SEM image (b) of $\mathrm{NiMn}_{2} \mathrm{O}_{4}$-alginate film.

The nano-biocomposite film morphology is shown in Figure $6 \mathrm{~b}$, where we can see the alginate film containing $\mathrm{NiMn}_{2} \mathrm{O}_{4}$ particles in the form of small clusters. The film thickness was estimated to be on average $0.2 \mathrm{~mm}$ from several measurements of the film peeled off the Kapton substrate using a micrometer.

\subsection{NTC Thermistor Properties}

The measured electrical resistance of the $\mathrm{NiMn}_{2} \mathrm{O}_{4}$ nano-biocomposite film sample decreased with increases in temperature in the measured range of $20-50{ }^{\circ} \mathrm{C}$, indicating a typical NTC behavior, and is shown as an inset in Figure 7. An Arrhenius equation commonly describes the reduction in DC resistance with temperature increase for a NTC material [1]:

$$
R=R_{\infty} e^{\mathrm{B} / T}
$$

where B represents the material constant (B-value) of the thermistor commonly estimated from the linear fit, $R_{\infty}$ is the resistance at infinite temperature and $T$ is the temperature expressed in Kelvin. The relationship between $\ln R$ and the reciprocal value of $T$ is shown in Figure 7, enabling linear fit of this dependence and estimation of the material constant value for the analyzed $\mathrm{NiMn}_{2} \mathrm{O}_{4}$ nano-biocomposite film to be $4523 \mathrm{~K}$. In commercial NTC thermistors the B-value is generally between 2000 and $5000 \mathrm{~K}$, though a high processing temperature is commonly required to obtain such values for thermistor ceramics [1]. The 
material constant value previously obtained for pure powder obtained by sol-gel combustion drop casting in a water suspension on the same test interdigitated electrodes was $4812 \mathrm{~K}$ [33]. Flexible substrates are not tolerant of the high temperatures commonly needed to obtain good NTC thermistor ceramics or thick films $[12,18]$. The use of flexible substrates requires a low processing temperature (up to $\approx 200{ }^{\circ} \mathrm{C}$, depending on the substrate used). Thus, it is necessary to obtain good temperature sensitivity of the drop cast layer at low temperatures, as was obtained for the synthesized $\mathrm{NiMn}_{2} \mathrm{O}_{4}$ nanocrystalline powder. The measured resistance for the nano-biocomposite film was overall lower, on average by three orders of magnitude, than the values previously obtained for the powder $(\approx 31$ to $7 \mathrm{M} \Omega$ in the temperature range of $20-50{ }^{\circ} \mathrm{C}$ [33], also at $\mathrm{RH} 50 \%$ ), ranging from $\approx 39 \mathrm{k} \Omega$ for $20^{\circ} \mathrm{C}$ to $\approx 10 \mathrm{k} \Omega$ for $50{ }^{\circ} \mathrm{C}$ at a relative humidity (RH) of $50 \%$, reflecting the influence of the alginate component, as shown in the inset in Figure 7. The material constant (B-value) estimated from the linear fit shown in Figure 7 as $4523 \mathrm{~K}$ was slightly lower than the value determined for the pure powder, but well within the range of commercial spinel based NTCR ceramics [1] and slightly higher than the value of $4379 \mathrm{~K}$ obtained for electrospun $\mathrm{NiMn}_{2} \mathrm{O}_{4}$ powder [46].

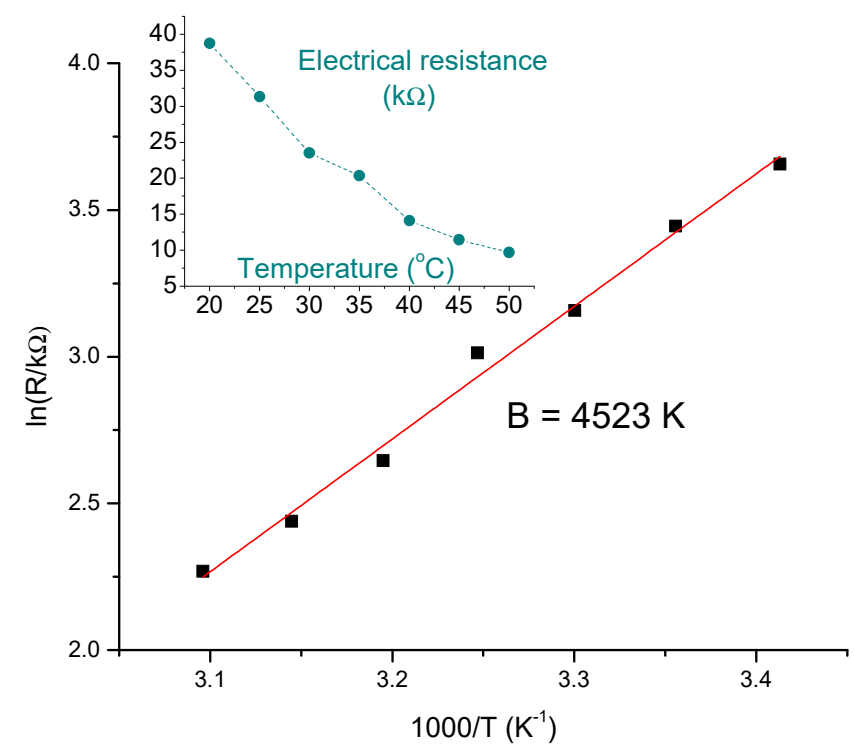

Figure 7. Fitting of the material constant (B) from the measured DC electrical resistance of $\mathrm{NiMn}_{2} \mathrm{O}_{4^{-}}$ alginate nano-biocomposite film shown in the inset using Equation (1).

The temperature sensitivity at room temperature $\left(25^{\circ} \mathrm{C}\right)$ was determined to be $-5.09 \% / \mathrm{K}$ by differentiation of equation (1) into:

$$
\alpha=\frac{1}{R} \frac{d R}{d T}=-\frac{\mathrm{B}}{T^{2}}
$$

This value was slightly lower than for the pure powder obtained by sol-gel combustion $\left(-5.4 \% / \mathrm{K}\right.$ [33]), slightly higher than for $\mathrm{NiMn}_{2} \mathrm{O}_{4}$ electrospun nanofibers $(-4.95 \% / \mathrm{K}$ [46]), comparable with commercial devices [1] and within the range previously determined for as-deposited and annealed $\mathrm{NiMn}_{2} \mathrm{O}_{4}$ thick films obtained by aerosol deposition [7,47].

\subsection{Impedance Dependence on Frequency and Temperature at a Constant RH of 50\%}

The change in impedance of the $\mathrm{NiMn}_{2} \mathrm{O}_{4}$-alginate nano-biocomposite film with frequency in the temperature range of $20-50{ }^{\circ} \mathrm{C}$ is shown in Figure $8 \mathrm{a}$. In the measured frequency range from $8 \mathrm{~Hz}$ to $\approx 100 \mathrm{kHz}$ the impedance decreased very gradually and reduced in the same way with temperature, showing that impedance can be the monitored parameter for temperature sensing in a wide frequency range. 


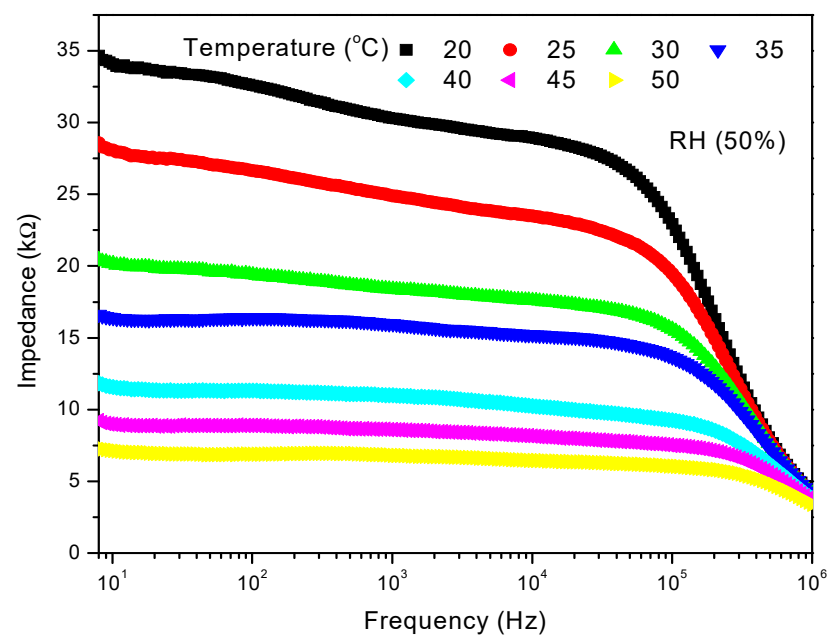

(a)

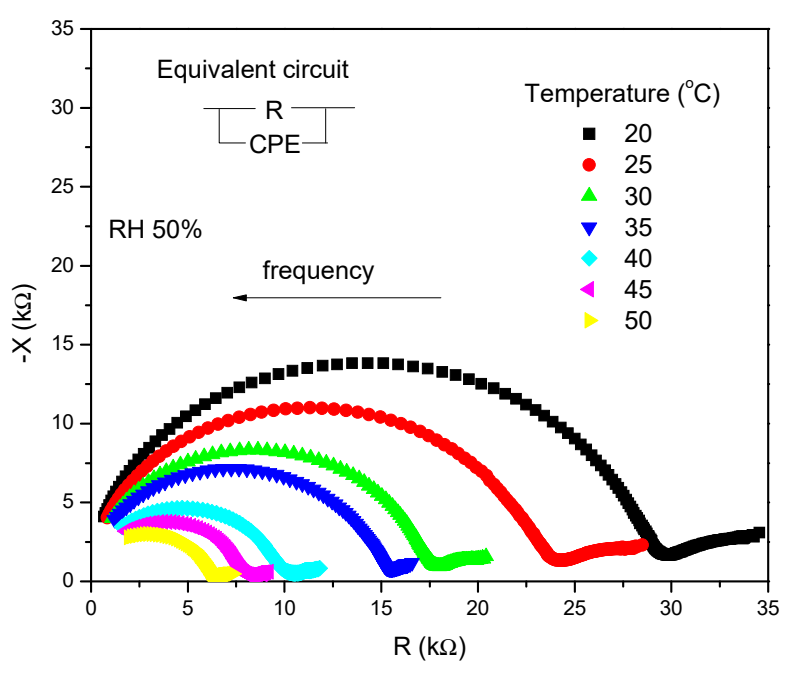

(b)

Figure 8. Impedance dependence on frequency at RH 50\% (a) and complex impedance (b) measured in the temperature range of $20-50{ }^{\circ} \mathrm{C}$; inset in (b) shows the applied equivalent circuit.

The complex impedance $(R+j X)$ in the temperature range of $20-50{ }^{\circ} \mathrm{C}$ is shown in Figure $8 \mathrm{~b}$. The larger semicircle at higher frequency and partial arcs at lower frequencies reflect the grain, grain boundary and electrode effects $[48,49]$. The grain effect dominated with a noticeable semicircle. This has been previously noted for nano-grained $\mathrm{Ni}_{0.54} \mathrm{Mn}_{1.26} \mathrm{Fe}_{1.2} \mathrm{O}_{4}$ NTC thermistors [48]. The grain boundary and electrode effects were smaller, and are evident as part of an arc and spur in the lower frequency range. The radius of the grain effect semicircle decreased visibly with temperature, confirming the strong negative thermal coefficient effect.

An equivalent circuit was used to analyze the grain effect, composed of a parallel resistance and Constant Phase Element (CPE) element. The CPE element is used in the case of non-ideal Debye behavior due to inhomogeneity $[49,50]$ when the semicircle is depressed with a center below the $x$-axis. This type of inhomogeneity is expected in a composite. The impedance of a CPE element can be defined as [49]:

$$
Z_{\mathrm{CPE}}=1 /(j \omega)^{n} \cdot Q
$$

where $n$ is the critical CPE exponent whose value is between 0 and $1, \omega$ is the angular frequency and $Q$ is the CPE parameter with the numerical value of admittance $1 /|Z|$ at $\omega=1 \mathrm{rad} / \mathrm{s}$. EIS Spectrum Analyzer Software [51] was used to fit the experimental data to the equivalent circuit. The real value of grain capacitance in the case of an equivalent circuit composed of a parallel resistance and CPE element is calculated from the values determined for $Q_{g}$ and $R_{g}$ as [50]:

$$
C_{g, C P E}=\left(Q_{g} \cdot R_{g}{ }^{-(n-1)}\right)^{1 / n}
$$

The determined values for the critical exponent $\left(n_{g}\right)$ were similar in the analyzed temperature range $\left(20-50{ }^{\circ} \mathrm{C}\right)$. They varied between 0.959 and 0.975 with an average value of 0.965 , similar to values determined by $\mathrm{Ryu}$ et al. for $\mathrm{NiMn}_{2} \mathrm{O}_{4}$ thin films [47]. The calculated capacity using Equation (4) was between 38.4 and 39.5 with an average value of $39 \mathrm{pF}$. This falls within the range predicted for grain capacity $\left(10^{-10}-10^{-12} \mathrm{~F}\right)$ [48]. The determined grain resistance $\left(R_{g}\right)$ decreased with increase in temperature $(T)$ and following Arrhenius dependence in accordance with the adiabatic small polaron hopping model [49]:

$$
R_{g} / T=A_{0} \cdot \exp \left(E_{g, a} / k T\right)
$$


where $A_{0}$ is a constant, $k$ is the Boltsmann constant and $E_{g, a}$ is the activation energy determined as shown in Figure 9 a to be $0.45 \mathrm{eV}$. This value is in accordance with the values determined by Zhang et al. for nano-grained $\mathrm{Ni}_{0.54} \mathrm{Mn}_{1.26} \mathrm{Fe}_{1.2} \mathrm{O}_{4}$ NTC thermistors [48].

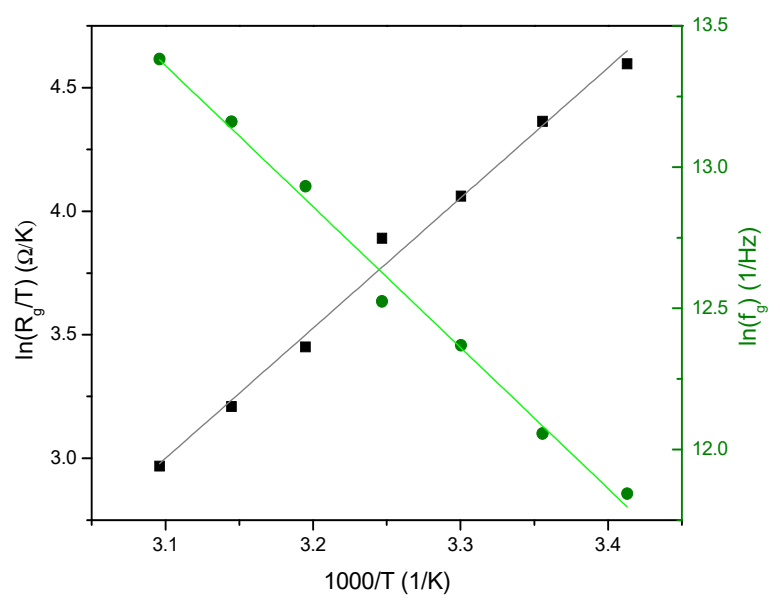

(a)

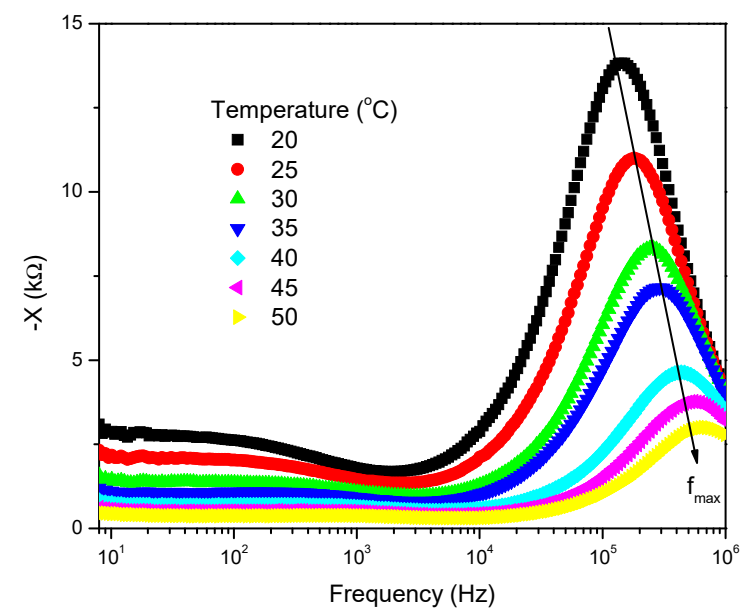

(b)

Figure 9. Temperature dependence of grain resistance $\left(R_{g}\right)$ and grain relaxation frequency $\left(f_{g}\right)(\mathbf{a})$ and frequency dependence of imaginary part of impedance $(\mathbf{b})$ of $\mathrm{NiMn}_{2} \mathrm{O}_{4}$-alginate nano-biocomposite thick film.

The grain relaxation frequency $\left(f_{g}\right)$ shifted with temperature to higher values (Figure $9 b$ ), also following the Arrhenius dependence [52]:

$$
f_{g}=A_{0} \cdot \exp \left(E_{f, a} / k T\right)
$$

where $A_{0}$ is a constant, $k$ is the Boltsmann constant and $E_{f, a}$ is the activation energy determined, as shown in Figure $9 \mathrm{a}$, to be $0.43 \mathrm{eV}$. At the same time, the relaxation time (reciprocal value of frequency) decreased, indicating the occurrence of electrical relaxation and thermally activated conduction in grains [49].

\subsection{Influence of Change in $\mathrm{RH} 40-90 \%$ on Impedance at a Constant Temperature of $25^{\circ} \mathrm{C}$}

Increases in relative humidity in the range of $40-90 \%$ at a constant temperature of $25^{\circ} \mathrm{C}$ were accompanied by a rapid decrease in both measured DC resistance (Figure 10a) and complex impedance (Figure 10b). The resistance decreased with increase in relative humidity from $\approx 104 \mathrm{k} \Omega$ at $\mathrm{RH} 40 \%$ to $\approx 0.6 \mathrm{k} \Omega$ at $\mathrm{RH} 90 \%$. $\mathrm{NiMn}_{2} \mathrm{O}_{4}$ has previously been shown to be a potential humidity-sensing material $[46,53]$. The time delay between adsorption (condensation) and desorption (evaporation) was low (1.5\%) with the curves almost overlapping, as shown in Figure 10a, indicating that the sensing material displayed a good hysteresis curve [34]. Analysis of the shape of the complex impedance curve with increase in $\mathrm{RH}$ (Figure 10b) shows that alongside the reduction in semicircle radius, its shape also changed, reflecting the influence of an increased number of water molecules on the porous nano-biocomposite surface and a change in the process mechanism. In the lower humidity range (40-60\%) the grain effect was dominant, with this semicircle gradually decreasing and becoming less dominant as the RH increased. For lower RH water molecules were first only chemisorbed on the surface, followed by physisorption, and with further increase in $\mathrm{RH}$ forming multiple physisorbed layers, resulting in proton hopping between water molecules [46], reduced resistance and impedance values and, in this case, increased dominance of the grain boundary and electrode effects. Increased capacitive behavior at the interface between the electrode and sensor material at high $\mathrm{RH}$ is due to diffusion and polarization of charged species [53]. 


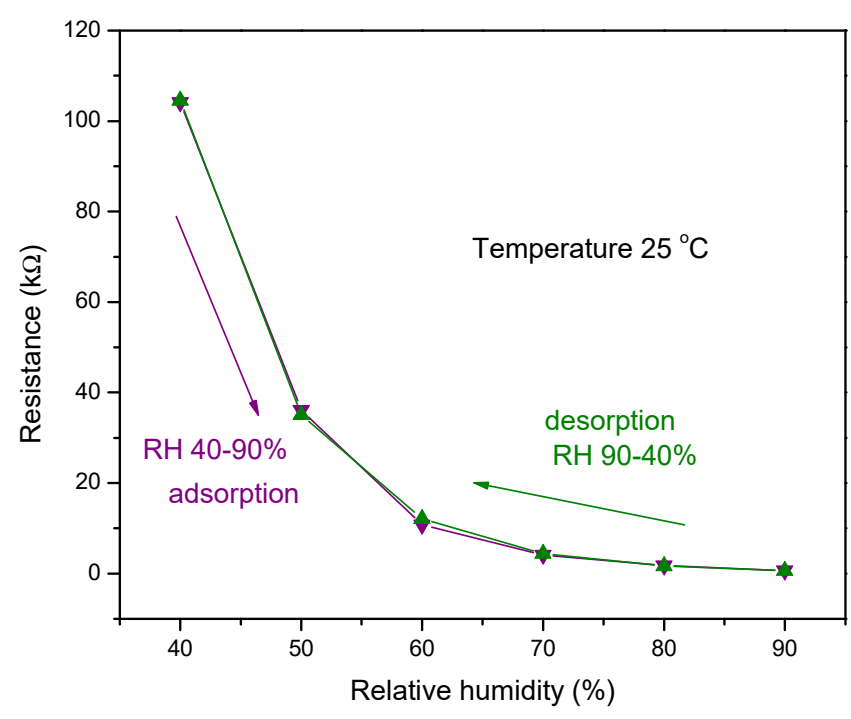

(a)

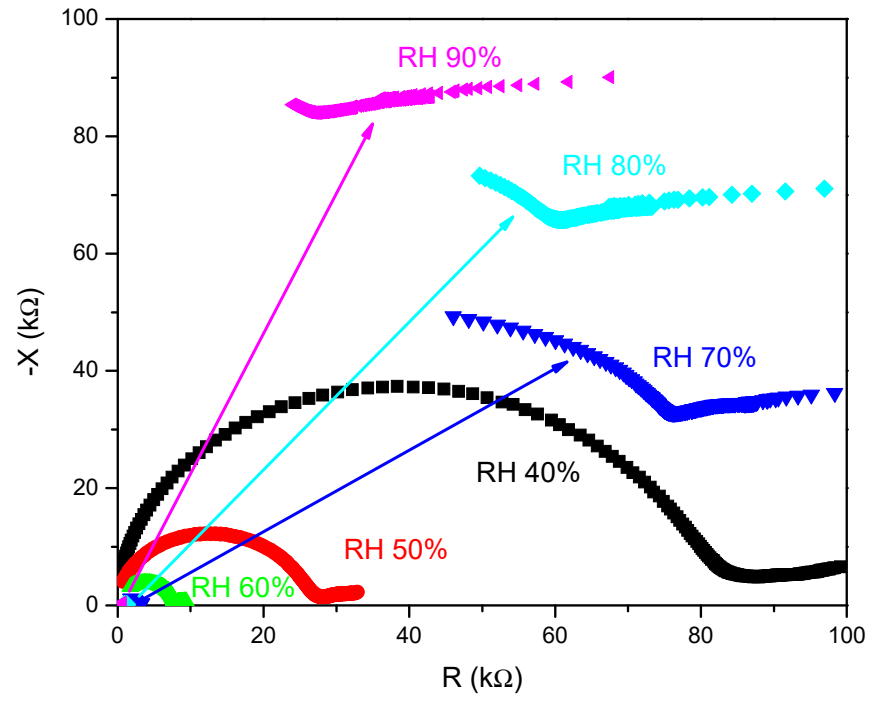

(b)

Figure 10. Adsorption and desorption curves obtained at $25^{\circ} \mathrm{C}$ in the $\mathrm{RH}$ range $40-90 \%$ (a) and influence of change in $\mathrm{RH}$ on complex impedance $(\mathbf{b})$.

\section{Conclusions}

In summary, a nickel manganite-alginate nano-biocomposite film with an average thickness of $0.2 \mathrm{~mm}$ was prepared by drop casting nanocrystalline nickel manganite synthesized via sol-gel combustion mixed with alginate gel onto a Kapton substrate. The obtained film was stable and flexible. Its capacity as a temperature sensing material was tested on an alumina substrate with small PdAg interdigitated electrodes. The material constant was determined to be $4523 \mathrm{~K}$ in the temperature range of $20-50{ }^{\circ} \mathrm{C}$, while the temperature sensitivity at room temperature was $-5.09 \% / \mathrm{K}$. Grains dominated the change in impedance and negative temperature effect. The activation energies for conduction and relaxation, determined from the evaluated grain resistance and relaxation frequency, were 0.45 and $0.43 \mathrm{eV}$ respectively, and followed the small polaron hopping model. Increase in relative humidity at a constant temperature reduced resistance and impedance. Future research will focus on drop casting the nickel manganite-alginate nano-biocomposite gel on different flexible substrates in order to test for a wide range of applications.

Author Contributions: Conceptualization, M.V.N.; M.P.D. and Z.Z.V. designed and performed material synthesis, film preparation, measured DC resistance and AC impedance; J.K. measured and analyzed XPS spectra; N.B.T. performed XRD characterization; M.V.N. measured and analyzed FT-IR spectra and performed SEM analysis; writing-original draft preparation, M.V.N.; writing-review and editing, Z.Z.V. and M.P.D. All authors have read and agreed to the published version of the manuscript.

Funding: This research was funded by the Ministry for Education, Science and Technology Development under the contract 451-03-9/2021-14/200053 (M.P.D., Z.Z.V. and M.V.N.).

Institutional Review Board Statement: Not applicable.

Informed Consent Statement: Not applicable.

Data Availability Statement: The data presented in this study are available on request from the corresponding author. The data are not publicly available due to ongoing research.

Acknowledgments: The authors would like to thank Smilja Markovic, ITS SASA and Gordana Tanasijevic, IMSI for help with FT-IR measurements of powder and nano-biocomposite samples, respectively. 
Conflicts of Interest: The authors declare no conflict of interest. The funders had no role in the design of the study; in the collection, analyses, or interpretation of data; in the writing of the manuscript; or in the decision to publish the results.

\section{References}

1. Feteira, A. Negative temperature coefficient resistance (NTCR) ceramic thermistors: An industrial perspective. J. Am. Ceram. Soc. 2009, 92, 967-983. [CrossRef]

2. Guan, F.; Wu, Y.; Milisavljevic, I.; Cheng, X.; Huang, S. Valence-induced effects on the electrical properties of $\mathrm{NiMn}_{2} \mathrm{O}_{4}$ ceramics with different Ni sources. J. Am. Ceram. Soc. 2021, 104, 5148-5156. [CrossRef]

3. Li, H.; Zhang, H.; Chang, A.; Ma, X.; Rong, J.; Yang, L. A novel core-shell structure NTC ceramic with high stability fabricating by an in-situ ink-jet printing method. J. Eur. Ceram. Soc. 2021, 41, 4167-4174. [CrossRef]

4. Schubert, M.; Münch, C.; Schuurman, S.; Poulain, V.; Kita, J.; Moos, R. Novel method for NTC thermistor production by aerosol co-deposition and combined sintering. Sensors 2019, 19, 1632. [CrossRef]

5. Schmidt, R.; Basu, A.; Brinkman, A.W. Small polaron hopping in spinel manganites. Phys. Rev. B 2005, 72, 115101. [CrossRef]

6. Fritsch, S.; Sarrias, J.; Brien, M.; Conderc, J.J.; Bandour, J.L.; Snoek, E.; Rousset, A. Correlation between the structure, the microstructure and the electrical properties of nickel manganite negative temperature coefficient (NTC) thermistors. Solid State Ion. 1998, 109, 229-237. [CrossRef]

7. Schubert, M.; Munch, C.; Schuman, S.; Poulain, V.; Kita, J.; Moos, R. Characterization of nickel manganite NTC thermistor films prepared by aerosol deposition at room temperature. J. Eur. Ceram. Soc. 2018, 38, 613-619. [CrossRef]

8. Liang, S.; Cao, C.; Yuan, Y.; Li, H.; Luo, M.; Gao, M.; Zhang, X. Hydrothermal synthesis of Zn-doped Ni-Mn-Al-O thin films toward high-performance negative temperature coefficient thermistor. J. Mater. Sci. Mater. Electron. 2018, 29, $9025-9032$. [CrossRef]

9. Aleksic, O.S.; Nikolic, M.V.; Lukovic, M.D.; Nikolic, N.; Radojcic, B.M.; Radovanovic, M.; Djuric, Z.Z.; Mitric, M.; Nikolic, P.M. Preparation and characterization of $\mathrm{Cu}$ and $\mathrm{Zn}$ modified nickel manganite NTC powders and thick film thermistors. Mater. Sci. Eng. B 2013, 178, 202-210. [CrossRef]

10. Ma, C.; Liu, Y.; Lu, Y.; Gao, H.; Qian, H.; Ding, J. Effect of Zn substitution on the phase, microstructure and electrical properties of $\mathrm{Ni}_{0.6} \mathrm{Cu}_{0.5} \mathrm{Zn}_{\mathrm{x}} \mathrm{Mn}_{1.9-\mathrm{x}} \mathrm{O}_{4}(0 \leq \mathrm{x} \leq 1) \mathrm{NTC}$ ceramics. Mater. Sci. Eng. B 2014, 188, 66-71. [CrossRef]

11. Katerinopolou, D.; Zalar, P.; Sweelssen, J.; Kiriakidis, G.; Rentorp, C.; Groen, P.; Gelinck, G.H.; van den Brand, J.; Smits, E.C.P. Large-area all-printed temperature sensing surfaces using novel composite thermistor materials. Adv. Electron. Mater. 2019, 5, 1800605. [CrossRef]

12. Shin, J.; Jeong, B.; Kim, J.; Nam, V.B.; Yoon, Y.; Jung, J.; Hong, S.; Lee, H.; Eom, H.; Yeo, J.; et al. Sensitive wearable temperature sensor with seamless monolithic integration. Adv. Mater. 2019, 2019, 19055271. [CrossRef] [PubMed]

13. Baldo, T.A.; Felipe de Lima, L.; Mendes, L.F.; de Araujo, W.R.; Paixao, T.R.L.C.; Coltro, W.K.T. Wearable and biodegradable sensors for clinical and environmental applications. ACS Appl. Electron. Mater. 2021, 3, 68-100. [CrossRef]

14. Majumder, S.; Mondal, T.; Jamal Deen, M. Wearable sensors for remote health monitoring. Sensors 2017, 17, 1301. [CrossRef]

15. Su, Y.; Ma, C.; Chen, J.; Wu, X.; Luo, W.; Peng, Y.; Luo, Z.; Peng, Y.; Luo, Z.; Li, L.; et al. Printable, highly sensitive flexible temperature sensors for human body temperature monitoring: A review. Nanoscale Res. Lett. 2020, 15, 200. [CrossRef] [PubMed]

16. Silva, A.F.; Tavakoli, M. Domiciliary hospitalization through wearable biomonitoring patches: Recent advances, technical challenges and the relation to COVID-19. Sensors 2020, 20, 6835. [CrossRef]

17. Kuzubasoglu, B.A.; Bahadir, S.K. Flexible temperature sensors: A review. Sens. Actuators A 2020, 315, 112282. [CrossRef]

18. Barmpakos, D.; Kaltsas, G. A review on humidity, temperature and strain printed sensors-Current trends and future perspectives. Sensors 2021, 21, 739. [CrossRef]

19. Chen, L.; Zhang, J. Designs of conductive polymer composites with exceptional reproducibility of positive temperature coefficient effect: A review. J. Appl. Polym. Sci. 2021, 138, e49677. [CrossRef]

20. Jeon, J.; Lee, H.B.R.; Bao, Z. Flexible wireless temperature sensors based on Ni microparticle filled binary polymer composite. Adv. Mater. 2013, 25, 850-855. [CrossRef]

21. Bibi, A.; Rehman, S.; Yaseem, A. Alginate nanoparticles composites: Kinds, reactions and applications. Mater. Res. Express 2019, 6, 092001. [CrossRef]

22. Liu, S.; Li, Y.; Li, L. Enhanced stability and mechanical strength of sodium alginate composite films. Carbohydr. Polym. 2017, 160, 62-70. [CrossRef]

23. Biondi, M.; Borzacchiello, A.; Mayol, L.; Ambrosio, L. Nanoparticle integrated hydrogels as multifunctional composite materials for biomedical applications. Gels 2015, 1, 162-178. [CrossRef]

24. Varaprasad, K.; Raghavendra, G.M.; Jayaramudu, T. Nano zinc oxide-sodium alginate antibacterial cellulose fibres. Carbohyrd. Polym. 2014, 135, 349-355. [CrossRef] [PubMed]

25. Aristazabal-Gil, M.V.; Santiago-Toro, S.; Sanchez, L.T.; Pinzon, M.I.; Gutierez, J.A.; Viela, C.C. ZnO and ZnO/CaO nanoparticles in alginate films. Synthesis, mechanical characterization, barrier properties and release kinetics. LWT Food. Sci. Technol. 2019, 112, 108217. [CrossRef]

26. Buk, V.; Euregul, E.; Euregul, K.C. Alginate copper oxide nano-biocomposite as a novel material for amperometric glucose biosensing. Mater. Sci. Eng. C 2017, 74, 307-314. [CrossRef] [PubMed] 
27. Varma, A.; Mukasyan, A.S.; Rogachev, A.S.; Manukyan, K.V. Solution combustion synthesis of nanoscale materials. Chem. Rev. 2016, 116, 14493-14586. [CrossRef] [PubMed]

28. Vamsi Krishna, B.N.; Bhagwan, J.; Yu, J.S. Sol-gel routed $\mathrm{NiMn}_{2} \mathrm{O}_{4}$ nanofabric electrode materials for supercapacitors. J. Electrochem. Soc. 2019, 166, A1950. [CrossRef]

29. Al-Senani, G.M.; Abd-Elkader, O.H.; Al-Kadhi, N.S.; Deraz, N.M. Effect of glycine treatment on synthesis and physicochemical characteristics of nanosized Ni-Mn mixed oxides. Crystals 2021, 11, 487. [CrossRef]

30. Momma, K.; Izumi, F. VESTA 3 for three dimensional visualization of crystal, volumetric and morphology data. J. Appl. Crystallogr. 2011, 44, 1271-1276. [CrossRef]

31. Sodium Alginate, 2D Structure. Available online: https://pubchem.ncbi.nlm.nih.gov / compound/5102882\#section=2D-Structure (accessed on 17 March 2021).

32. Sodium Alginate, 3D Conformer. Available online: https://pubchem.ncbi.nlm.nih.gov/compound/5102882\#section=3DConformer (accessed on 17 March 2021).

33. Nikolic, M.V.; Vasiljevic, Z.Z.; Dojcinovic, M.P.; Tadic, N.B.; Radovanovic, M.; Stojanovic, G.M. Nanocrystalline nickel manganite synthesis by sol-gel combustion for flexible temperature sensors. In Proceedings of the 2020 IEEE International Conference on Flexible and Printable Sensors and Systems (FLEPS), Manchester, UK, 16-19 August 2020. [CrossRef]

34. Nikolic, M.V.; Dojcinovic, M.P.; Vasiljevic, Z.Z.; Lukovic, M.D.; Labus, N.J. Nanocomposite $\mathrm{Zn}_{2} \mathrm{SnO}_{4} / \mathrm{SnO}_{2}$ thick films as a humidity sensing material. IEEE Sens. J. 2020, 20, 7509-7516. [CrossRef]

35. Vijaya Sankar, K.; Suren Idran, S.; Pandi, K.; Allin, A.M.; Nithya, V.D.; Lee, Y.S.; Kalai Selvan, R. Studies on the electrochemical intercalation/de-intercalation mechanism of $\mathrm{NiMn}_{2} \mathrm{O}_{4}$ for high stable pseudocapacitor electrodes. RSC Adv. 2015, 5, 27649-27656. [CrossRef]

36. Mhin, S.; Han, H.; Kim, K.M.; Lim, J.; Kim, D.; Lee, J.I.; Ryu, J.H. Synthesis of (Ni, Mn,Co) $\mathrm{O}_{4}$ nanopowder with single cubic phase via combustion method. Ceram. Int. 2016, 42, 13654-13658. [CrossRef]

37. Komova, O.V.; Simagina, V.I.; Mukha, S.S.; Netskina, O.V.; Odegova, G.V.; Bularchenko, O.A.; Ishchenko, A.V.; Pochtar, A.A. A modified glycine-nitrate combustion method for one-step synthesis of $\mathrm{LaFeO}_{3}$. Adv. Powder Technol. 2016, 27, 496-503. [CrossRef]

38. Savic, S.M.; Nikolic, M.V.; Paraskevopoulos, K.M.; Zorba, T.T.; Nikolic, N.; Blagojevic, V.; Aleksic, O.S.; Brankovic, G. Far infrared and microstructural studies of mechanically activated nickel manganite. Ceram. Int. 2013, 39, 1241-1247. [CrossRef]

39. Moulder, J.F.; Stickle, W.F.; Sobol, P.E.; Bomben, K.D. Handbook of X-ray Photoelectron Spectroscopy; Physical Electronics Inc.: Eden Prairie, MN, USA, 1995.

40. Zhang, M.; Guo, S.; Zheng, L.; Zhang, G.; Hao, Z.; Kang, L.; Liu, Z.H. Preparation of $\mathrm{NiMn}_{2} \mathrm{O}_{4}$ with large specific surface area from an epoxide driven sol-gel process and its capacitance. Electrochim. Acta 2013, 87, 546-553. [CrossRef]

41. Toepfer, J.; Feltz, A.; Graef, D.; Hacke, B.; Rampach, L.; Weissbrodt, P. Cation valences and distribution in the spinels $\mathrm{NiMn}_{2} \mathrm{O}_{4}$ and $\mathrm{M}_{\mathrm{z}} \mathrm{NiMn}_{2-\mathrm{z}} \mathrm{O}_{4}(\mathrm{M}=\mathrm{Li}, \mathrm{Cu})$ studied by XPS. Phys. Stat. Sol. 1992, 134, 405. [CrossRef]

42. Lisboa-Filho, P.N.; Bahout, M.; Barahora, P.; Moure, C.; Pena, O. Oxygen stoichiometry effects in spinel type $\mathrm{NiMn}_{2} \mathrm{O}_{4-\delta}$ samples. J. Phys. Chem. Sol. 2005, 66, 1206-1212. [CrossRef]

43. Papageorgiu, S.K.; Kouvelos, E.P.; Favvas, E.P.; Sagalidis, A.A.; Romanos, G.E.; Katsavos, F.K. Metal-carboxylate interactions in metal-alginate complexes studied with FTIR spectroscopy. Carbohydr. Res. 2010, 345, 469-473. [CrossRef]

44. Xiao, Q.; Gu, X.; Tan, S. Drying process of sodium alginate films studied by two-dimensional correlation ATR-FTIR spectroscopy. Food. Chem. 2014, 164, 179-184. [CrossRef]

45. Ionita, M.; Pandele, M.A.; Iovu, H. Sodium alginate/graphene oxide composite films with enhanced thermal and mechanical properties. Carbohydr. Polym. 2013, 94, 339-344. [CrossRef] [PubMed]

46. Dojcinovic, M.P.; Vasiljevic, Z.Z.; Krstic, J.B.; Vujancevic, J.D.; Markovic, S.; Tadic, N.B.; Nikolic, M.V. Electrospun nickel manganite $\left(\mathrm{NiMn}_{2} \mathrm{O}_{4}\right)$ nanocrystalline fibers for humidity and temperature sensing. Sensors 2021, 21, 4351. [CrossRef] [PubMed]

47. Ryu, J.; Park, D.S.; Schmidt, R. In-plane impedance spectroscopy in aerosol deposited $\mathrm{NiMn}_{2} \mathrm{O}_{4}$ negative temperature coefficient thermistor films. J. Appl. Phys. 2011, 109, 113722. [CrossRef]

48. Zhang, X.; Yao, S.; Zhao, D.; Liang, S. Nano-negative temperature coefficient thermistor with unique electrical properties of high B constant and low resistivity. J. Mater. Sci. Mater. Electron. 2021, 32, 5222-5232. [CrossRef]

49. Zeng, Y.; Li, Z.; Shao, Z.; Wang, X.; Hao, W.; Zhang, H. Electrical properties of $\mathrm{YFeO}_{3}$ based ceramics modified by $\mathrm{Cu} / \mathrm{Nb}$ ions as negative temperature coefficient thermistors. J. Mater. Sci. Mater. Electron. 2019, 30, 14528-14537. [CrossRef]

50. Nikolic, M.V.; Sekulic, D.L.; Vasiljevic, Z.Z.; Lukovic, M.D.; Pavlovic, V.B.; Aleksic, O.S. Dielectric properties, complex impedance and electrical conductivity of $\mathrm{Fe}_{2} \mathrm{TiO}_{5}$ nanopowder compacts and bulk samples at elevated temperatures. J. Mater. Sci. Mater. Electron. 2017, 28, 4796-4806. [CrossRef]

51. Bondarenko, A.S.; Ragoisha, G. EIS Spectrum Analyzer. Available online: https://www.abc.chemistry.bsu.by (accessed on 25 November 2016).

52. He, L.; Ling, Z. Studies of temperature dependent ac impedance of a negative temperature coefficient Mn-Co-Ni-O thin film thermistor. Appl. Phys. Lett. 2011, 98, 242112. [CrossRef]

53. Gawli, Y.; Badadhe, S.; Basu, A.; Guin, D.; Shelke, M.V.; Ogale, S. Evaluation of n-type ternary metal oxide $\mathrm{NiMn}_{2} \mathrm{O}_{4}$ nanomaterial for humidity sensing. Sens. Actuators B 2014, 191, 837-843. [CrossRef] 